\title{
Rational water use by applying regulated deficit and partial root-zone drying irrigation techniques in tomato under arid conditions
}

\author{
Mahmoud S. Hashem ${ }^{1,2 *}$, Tarek Zin El-Abedin ${ }^{1,3}$, and Hussein M. Al-Ghobari ${ }^{1}$ \\ ${ }^{1}$ King Saud University, College of Food and Agriculture Sciences, Agricultural Engineering Department, PO Box 2460, Riyadh 11451, \\ Saudi Arabia. Corresponding author (mahmoudsabry375@gmail.com). \\ ${ }^{2}$ Agricultural Research Center, Agricultural Engineering Research Institute, PO Box 256, Giza, Egypt. \\ ${ }^{3}$ Alexandria University, College of Agriculture, Agricultural Engineering Department, PO Box 21545, Alexandria, Egypt.
}

Received: 2 May 2018; Accepted: 22 August 2018; doi:10.4067/S0718-58392019000100075

\begin{abstract}
This study involved exploring the opportunities of using regulated deficit irrigation and partial root zone drying approaches as water-saving irrigation methods in a tomato crop (Solanum lycopersicum L.) based on irrigation scheduling. The Partial Root Zone Drying Irrigation practice simply involved interchanging the wet and dry sides in subsequent irrigations. The field experiment was conducted in the Kingdom of Saudi Arabia, during the fall season of 2014-2015 and 2015-2016. The following three irrigation treatments were tested during both years under a drip irrigation system: (1) full irrigation (FI), as a control treatment; (2) regulated deficit irrigation (RDI); and (3) partial root zone drying irrigation (PRD). Both RDI and PRD treatments received $70 \%$ of the irrigation water volume of full irrigation (FI). The obtained results indicated that the soil water content of PRD treatment was higher and conserved more soil moisture than that in the RDI treatment. Data for both years indicated that FI exhibited the highest stomatal conductance $\left(\mathrm{g}_{\mathrm{s}}\right)$ values while PRD exhibited the lowest $\mathrm{g}_{\mathrm{s}}$ values among all the treatments. Under PRD treatment, the dry fruit yield was the highest when compared with RDI and FI treatments for both years. Deficit irrigation treatments result in higher abscisic acid (ABA) concentration in the xylem when compared to that in FI. The vast majority of most extreme irrigation water use efficiency (IWUE) values were involved with PRD while most of the minimum IWUE values were coupled with FI. These results indicate the effects of deficit level irrigation on IWUE.
\end{abstract}

Key words: Full irrigation, irrigation water use efficiency, partial root zone drying, regulated deficit irrigation, Solanum lycopersicum.

\section{INTRODUCTION}

Water is a central issue on the international agenda for several years. Recently, several parts of the world are affected by water shortage. Available water resources are subjected to an ever-increasing pressure as a result of increasing agricultural water demand for irrigated lands. A long-term perspective with respect to scarcity of fresh water resources especially in the arid and semi-arid areas, demands an urgent solution for new irrigation strategy and agricultural water management (Sepaskhah and Ahmadi, 2010).

The deliberate withholding of irrigation water by a technique known as deficit irrigation (DI) is an effective management approach to manipulate crop water use. PRD differs from RDI as it simultaneously maintains a wet as well as a drying portion of the root zone while RDI strategies create a level of moisture deficit throughout the root zone (White, 2007).

Tomato (Solanum lycopersicum L.) is one of the most important vegetables in the world, and it has high water requirements. It is typically grown in Saudi Arabia during fall and spring seasons. The successful irrigation of a tomato 
crop requires knowledge of both irrigation system and scheduling methods. Improved irrigation methods save water without undermine yield or quality.

Deficit irrigation (DI) is a watering strategy that was proposed many years ago to improve water efficiency and reduce the application of irrigation. In a broad sense, English and Raja (1996) state that DI consists of the deliberate and systematic under-irrigation of crops. Thus, the amount of water that is applied is lower than that needed to satisfy the full crop water requirements. As widely-known, reductions in the water applied generally lowers evapotranspiration (ET) and crop growth rates by limiting their principal component, namely transpiration, and thereby $\mathrm{C}$ assimilation. Therefore, the right application of DI needs a thorough understanding of the crop responses to water deficits and the profitable impact of reductions in crop value (Ruiz-Sanchez et al., 2010). Regulated deficit irrigation (RDI) is an irrigation approach to manipulate vegetative growth, yield, and quality with water stress. RDI was successfully employed to maximize WUE and achieve higher yields per unit of irrigation water in different crops (Afshar et al., 2014). With respect to the optimal application of RDI plant and soil, it is necessary to monitor water status to maintain a plant water regime within a certain degree of water stress that does not limit yield. This is the major difficulty when RDI is applied in field conditions.

Specifically, PRD is an irrigation strategy based on split-root technology that involves alternatively wetting and drying at least two spatially separate parts of a plant's root system. The aim of this strategy involves simultaneously maintaining plant water status at the maximum water potential while regulating stomatal behavior and vegetative growth (Kriedemann and Goodwin, 2003). This indicates that half of the root zone is irrigated and the other half is allowed to dry out. The frequency of the switch is determined based on the soil type, genotypes, or other factors such as rainfall and temperature.

If only a part of the root system dries and the remaining roots are maintained as well-watered, the chemical signals manufactured in the drying roots theoretically reduce stomatal aperture and control the vegetative vigor (Wakrim et al., 2005). This mechanism optimizes water use and increases WUE (Shahabian et al.,2012). Thus, the PRD technique achieves the desired change in plant physiological response by elevating abscisic acid (ABA) as a feed-forward mechanism.

Practical results indicated that crops under PRD produced better yields than those under RDI when the same volume of irrigation water is applied (Liu et al., 2006). However, other studies compared PRD and RDI in grapevines and indicated slight or no improvement in crop yield and fruit quality when PRD was used as opposed to RDI (Romero et al., 2014).

The creation of soil moisture gradient is important to explore the beneficial effects of PRD irrigation. Zegbe-Domínguez et al. (2003) reported that the soil water content (SWC) were significantly lower in RDI and in the non-irrigated part of PRD treatment when compared to those in FI.

RDI and PRD are two water saving irrigation techniques that increase the WUE of potatoes, even without declining yield (Shahnazari et al., 2007). Salghi et al. (2012) showed that when compared to the control (control treatment that received $100 \%$ of its daily water requirement), RDI (received $50 \%$ of its daily water requirement) and PRD (received $50 \%$ of its daily water requirement) treatments increase the WUE to $150 \%$ and $166 \%$ for the RDI and PRD treatments, respectively, with respect to the tomato plant.

Partial stomatal closure occurs due to increased ABA. Accumulated evidence proposes that both hydraulic and chemical signals are operative and integrated into the regulation of leaf growth and stomatal conductance $\left(\mathrm{g}_{\mathrm{s}}\right)$ when plants are grown under drought stress (Comstock, 2002).

The aim of the present study included exploring the possibilities of using the RDI and PRD methods as a water-saving irrigation technique in a tomato crop based on irrigation scheduling and also comparing the responses of the tomato crop to PRD, RDI and FI under a drip irrigation system in terms of the physiology and productivity of crops and the amount of water saved.

\section{MATERIALS AND METHODS}

The experiment was conducted in an experimental field at an educational farm of the Faculty of Food and Agriculture Sciences, King Saud University, Riyadh ( $24^{\circ} 44^{\prime}$ N, $46^{\circ} 36^{\prime}$ E; 665 m a.s.l.), Kingdom of Saudi Arabia. The climate is typical of arid areas. The soil was prepared based on the standard methods for plowing, grading, and leveling.

The soil at the experimental site corresponded to sandy loam. Soil samples were collected at $20 \mathrm{~cm}$ up to a total depth of $60 \mathrm{~cm}$ to determine physical and chemical analyses based on standard methods. The physical analysis investigation included soil texture, field capacity $(\mathrm{FC})$, permanent wilting point $\left(\mathrm{W}_{\mathrm{P}}\right)$, saturated hydraulic conductivity $(\mathrm{KS})$, saturation 
moisture content $(\mathrm{S})$, and bulk density $(\mathrm{\rho b})$. Chemical analyses included examinations of anions, cations, $\mathrm{pH}$, electrical conductivity (EC), organic matter, total $\mathrm{N}$ content, and available N, P and K. The physical and chemical properties, soil fertility, and organic properties are shown in Tables 1,2, and 3.

An area of $102.7 \mathrm{~m}^{2}(13 \mathrm{~m} \times 7.9 \mathrm{~m})$ was located for the experiment to manage three treatments, each of which was repeated three times. A surface drip irrigation was applied to the established field. The field was divided into three plots. Each plot was divided into three rows, and each row contained 26 plants spaced $0.5 \mathrm{~m}$ apart (Figure 1).

The experiment consisted of three regimes, namely regular deficit irrigation (RDI), partial root zone drying irrigation (PRD), and full irrigation (FI). Both RDI and PRD treatments received 70\% of the irrigation water volume of FI. Each treatment was repeated three times. The statistical design used in the experiment was a completely randomized block design. The number of experimental units corresponded to nine units. All water treatments were applied either from one side as in FI and RDI or from both sides as in PRD irrigation. Drip lines with a diameter of $18 \mathrm{~mm}$ with in-line emitters spaced at a distance of $0.50 \mathrm{~m}$ were each delivered $8 \mathrm{~L} \mathrm{~h}^{-1}$ at an operating pressure of $100 \mathrm{kPa}$. Drip lines were placed at the centers of adjacent crop rows and separated by a distance of $0.7 \mathrm{~m}$ in the experimental plots for both FI and RDI treatments. However, the PRD treatment included two drip lines for each row of vegetables, and the distance between the two lateral lines was $0.4 \mathrm{~m}$. These two laterals were laid shiftily from each other by $25 \mathrm{~cm}$, and therefore the emitters correspond to a nested shape, and these two laterals were controlled by a separate valve. The buffer treatment was $0.75 \mathrm{~m}$.

The implementation of PRD irrigation systems necessitates that each row of vegetable is served by dual dripper lines in which each works independently. The irrigation under PRD treatment shifted from one side of the plants to the other every $7 \mathrm{~d}$ (Liu et al., 2006) to achieve a long-term effect of PRD on leaf gas exchange, abscisic acid (ABA) signaling, and WUE in the tomato crop.

The irrigation operation was automatically controlled through an automatic controller (ESP-LXME controllers, Rain Bird Corporation, Tucson, Arizona, USA) that was connected with a central control software (IQ v2.0, Rain Bird Corporation, Azusa, California, USA), and the software monitored and adjusted watering schedules for controllers and site from a compatible Windows PC. The water requirement for irrigation was automatically calculated as potential

Table 1. Physical properties of the soil.

\begin{tabular}{|c|c|c|c|c|c|c|c|c|c|}
\hline \multirow[b]{2}{*}{ Depth } & \multicolumn{3}{|c|}{ Particle size } & \multirow[b]{2}{*}{ Texture } & \multirow[b]{2}{*}{$\mathrm{FC}$} & \multirow[b]{2}{*}{$\mathrm{W}_{\mathrm{P}}$} & \multirow[b]{2}{*}{$\mathrm{KS}$} & \multirow[b]{2}{*}{$\mathrm{S}$} & \multirow[b]{2}{*}{$\rho b$} \\
\hline & Sand & Silt & Clay & & & & & & \\
\hline $\mathrm{cm}$ & 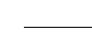 & $-\%$ & 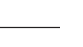 & & 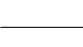 & 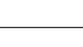 & $\mathrm{mm} \mathrm{h}^{-1}$ & $\%$ & $\mathrm{~g} \mathrm{~cm}^{-3}$ \\
\hline $0-20$ & 71.80 & 16.32 & 11.88 & Sandy loam & 19.71 & 9.68 & 35.78 & 35.12 & 1.62 \\
\hline $20-40$ & 66.72 & 18.02 & 15.26 & Sandy loam & 23.80 & 13.75 & 23.63 & 42.14 & 1.63 \\
\hline $40-60$ & 69.10 & 18.31 & 12.59 & Sandy loam & 25.41 & 15.47 & 18.59 & 43.13 & 1.63 \\
\hline
\end{tabular}

FC: Field capacity; $\mathrm{W}_{\mathrm{p}}$ : permanent wilting point; KS: saturated hydraulic conductivity; S: saturation moisture content; $\rho$ : bulk density.

Table 2. Fertility-related properties of the soil.

\begin{tabular}{cccccc}
\hline & & \multicolumn{3}{c}{ Fertility } & \\
\cline { 3 - 4 } Depth & $\mathrm{CaCO}_{3}$ & $\mathrm{~N}$ & $\mathrm{P}$ & $\mathrm{K}$ & Organic matter \\
\hline $\mathrm{cm}$ & $\%$ & & $\mathrm{mg} \mathrm{kg}^{-1}$ & \\
$0-20$ & 18.61 & 19.60 & 0.30 & 57.97 & 0.16 \\
$20-40$ & 23.39 & 14.52 & 0.70 & 66.82 & 0.10 \\
$40-60$ & 14.05 & 13.88 & 0.70 & 59.50 & 0.00 \\
\hline
\end{tabular}

Table 3. Chemical properties of the soil.

\begin{tabular}{|c|c|c|c|c|c|c|c|c|}
\hline \multirow[b]{2}{*}{ Depth } & \multicolumn{4}{|c|}{ Cations } & \multicolumn{4}{|c|}{ Anions } \\
\hline & $\mathrm{Ca}^{2+}$ & $\mathrm{Mg}^{2+}$ & $\mathrm{Na}^{+}$ & $\mathrm{K}^{+}$ & $\mathrm{HCO}_{3}^{-}$ & $\mathrm{CO}_{3}^{-}$ & $\mathrm{Cl}^{-}$ & $\mathrm{SO}_{4}{ }^{-}$ \\
\hline $\mathrm{cm}$ & \multicolumn{4}{|c|}{$\mathrm{cmol} \mathrm{L}^{-1}$} & \multicolumn{4}{|c|}{$\longrightarrow \mathrm{cmol} \mathrm{L}^{-1}$} \\
\hline $0-20$ & 12.00 & 3.60 & 11.66 & 0.48 & 1.40 & 0.00 & 11.50 & 32.30 \\
\hline $20-40$ & 11.50 & 3.50 & 11.88 & 0.57 & 1.30 & 0.00 & 10.50 & 25.20 \\
\hline $40-60$ & 11.70 & 4.50 & 9.34 & 0.37 & 1.10 & 0.00 & 11.00 & 16.80 \\
\hline
\end{tabular}


Figure 1. Experimental layout.

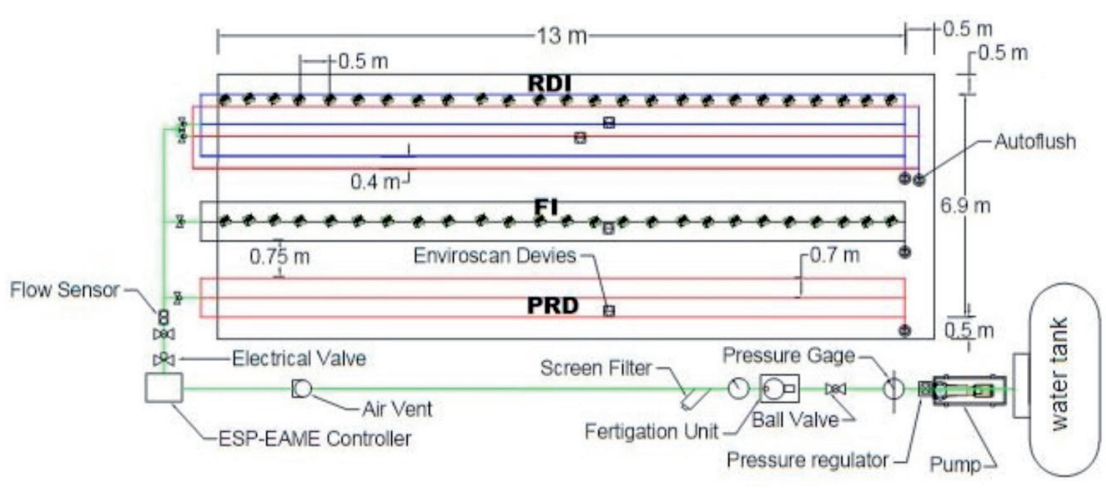

RDI: Regulated deficit irrigation; FI: full irrigation; PRD: partial root zone drying irrigation.

crop evapotranspiration $\left(\mathrm{ET}_{\mathrm{c}}\right)$ from an $\mathrm{ET}_{\mathrm{o}} \mathrm{FAO}$ Penman-Monteith equation based on climatic data obtained from the meteorological station (WS-PRO LT Weather Station, Rain Bird), which was established in the experiment field. The standard $\mathrm{K}_{\mathrm{c}}$ for each growth stage (initial, mid, and end) of the tomato crop was took from FAO-56 (Allen et al., 1998).

Soil moisture content in the experiments was monitored using capacitance probes (EnviroSCAN Sentek Sensor Technologies, Stepney, South Australia, Australia). Each EnviroSCAN includes five sensors installed at depths of 10, 20, 30,40 , and $50 \mathrm{~cm}$. Just one replicate was monitored from the three of each treatment. Four EnviroSCAN devices were installed in the field and used an EnviroSCAN device with each treatment with the single drip line (FI and RDI) and two EnviroSCAN devices with treatments with the dual drip line (PRD). The two devices were placed at a distance of $40 \mathrm{~cm}$ in a diagonal direction. Soil water data were sampled at a frequency that was set at $15 \mathrm{~min}$ between readings. The data were then stored in EnviroSCAN's custom built logging system.

The experiment was performed in the experimental field during the fall season of the year 2014-2015 and fall season of the year 2015-2016. The crop corresponded to tomato (Lycopersicon esculentum L.) Tomato seeds were germinated in commercial pellets (one seed per pellet; Jiffy-7, Jiffy, Oslo, Norway) in a controlled environment greenhouse. The seed was planted 4 wk prior to transferring the same to the open field. The greenhouse was located in the Dirab area near Riyadh in the Research and Agricultural Experiment Center, College of Food and Agriculture Sciences, King Saud University. The pellets were observed daily to maintain moisture and to observe any problem. After $4 \mathrm{wk}$, seedlings were transferred to sustainable land in the experiment field after field-preparation steps (e.g., watering, lining, and digging). The distance of planting corresponded to $50 \mathrm{~cm}$ within the line and $70 \mathrm{~cm}$ between lines.

The actual date of planting in the first year corresponded to 23 September 2015, and harvesting was performed from 19 December 2015 to 23 January 2016. In the second year, the actual date of planting corresponded to 23 September 2016, and harvesting occurred from 25 December 2016 to 25 January 2017. Common cultural practices including fertilizer application and insects and diseases control were conducted. The tomato crop was harvested seven times in the $1^{\text {st }}$ year and eight times in $2^{\text {nd }}$ year.

After commencing the treatments for the tomato crop, stomatal conductance $\left(\mathrm{g}_{\mathrm{s}}\right)\left(\mathrm{mol} \mathrm{m} \mathrm{m}^{-2} \mathrm{~s}^{-1}\right)$, and transpiration rate (T) $\left(\mathrm{mmol} \mathrm{m}^{-2} \mathrm{~s}^{-1}\right)$ were measured by using LI-6400XT portable photosynthesis system (LI-COR Corporate, Lincoln, Nebraska, USA). The measurements were monitored six times (from 11 November 2015 to 16 December 2015) during the treatment period for the $1^{\text {st }}$ year and 6 times (from 23 November 2016 to 28 December 2016) during the treatment period for $2^{\text {nd }}$ year. The measurement of gas-exchange were performed in each plot and was repeated thrice for each plot. The measurements were collected between $06: 00$ and $12.00 \mathrm{~h}$ local time. Within each plot, the third fully expanded upper canopy leaflets were selected for measurements. A total of nine plants were sampled per round, and the time period corresponded to approximately $0.5 \mathrm{~h}$.

In order to collect the xylem sample from tomatoes, a new approach was adopted in which the xylem sap was collected from the cut stems (Ahmadi et al., 2010). One stem per plot was sampled through the gas exchange measurements in the same plot (1 December, $67 \mathrm{~d}$ after transplanting) for the different irrigation treatments in both years. In order to collect approximately $0.5-1.0 \mathrm{~mL}$ xylem sap, an overpressure of approximately 0.2-0.4 MPa above the plant equilibrium 
pressure was applied, and sap was collected using an appropriate pipette (Liu et al., 2006). The xylem ABA samples were immediately frozen in liquid nitrogen and subsequently stored at $-80^{\circ} \mathrm{C}$ until the analysis. All samples were used to determine ABA content through an enzyme-linked immunosorbent assay (ELISA) (Asch, 2000).

Fruits were manually collected from each line, weighed, and counted to determine fresh weight and fruit per plant. Number of fruits and fruit weight per plant and the total fresh fruit yield (all the collected fruits) were determined. Harvest-ripe fruits were manually picked and weighed twice a week from 19 December in the $1^{\text {st }}$ year and 25 December in the $2^{\text {nd }}$ year, and this continued until the end of the experiment for both. The dry weight of tomato fruits was determined after oven drying for $48 \mathrm{~h}$ at $80^{\circ} \mathrm{C}$. Therefore, yield components characters were: Total fresh fruit yield $\left(\mathrm{Mg}^{-1}\right)$, total dry fruit yield $\left(\mathrm{Mg} \mathrm{ha}^{-1}\right)$, and number of fruits per plant.

The most important indicator that demonstrates the benefit of a treatment was the irrigation water use efficiency (IWUE) defined as the ratio of crop yield over the applied water (De Pascale et al., 2011) as a function of yield (Y; $\mathrm{kg}$ ) and applied water $\left(\mathrm{AW} ; \mathrm{m}^{3}\right)$. The AW was measured by the flow sensor installed in the field.

The data were subjected to ANOVA by using SPSS Statistics (IBM, Armonk, New York, USA). The least significant difference (LSD) test at $\mathrm{p}<0.05$ was applied to determine significant differences among the means of irrigation treatment.

\section{RESULTS AND DISCUSSION}

Soil water distribution of different patterns in response to tomatoes irrigation treatments (FI, RDI, and PRD) during 2 yr was continuously monitored by using EnviroSCAN probes. This offered a nondestructive and less tedious method to continuously monitor water content within and below the root zone. Consequently, data were recorded for soil water content (SWC) values that were plotted relative to the number of days after planting. This period was divided into four growth stages, namely the initial $26 \mathrm{~d}$, development $30 \mathrm{~d}$, mid-season $30 \mathrm{~d}$, and late season $38 \mathrm{~d}$, as shown in Figures 2 and 3. The SWC was measured at five soil depths, namely 10, 20,30,40, and $50 \mathrm{~cm}$. The average of SWC of these depths was calculated and illustrated as shown in Figures 2 and 3. Field capacity and permanent wilting point were also simultaneously plotted to show the status of plant stress due to the irrigation treatment. Generally, the initial stage and most of the development stage were almost similar to each other for the first and second years respectively, while all treatments received the same amount of water that corresponded to $100 \%$ ET.

Evidently, the level of SWC immediately decreased in the root zone after deficit irrigation treatments were applied and was less than that in full irrigation treatment. Conversely, the rate of the SWC constantly decreased when plant growth increased and the uptake of water increased. As observed in all the SWC treatments graphs, the SWC was at an acceptable

Figure 2. Soil water content (SWC) distribution in tomatoes field under different irrigation treatments: full irrigation (FI), regulated deficit irrigation (RDI), and partial root zone drying irrigation (PRD) in the $1^{\text {st }}$ year from the $1^{\text {st }}$ day until $123 \mathrm{~d}$ after transplanting.

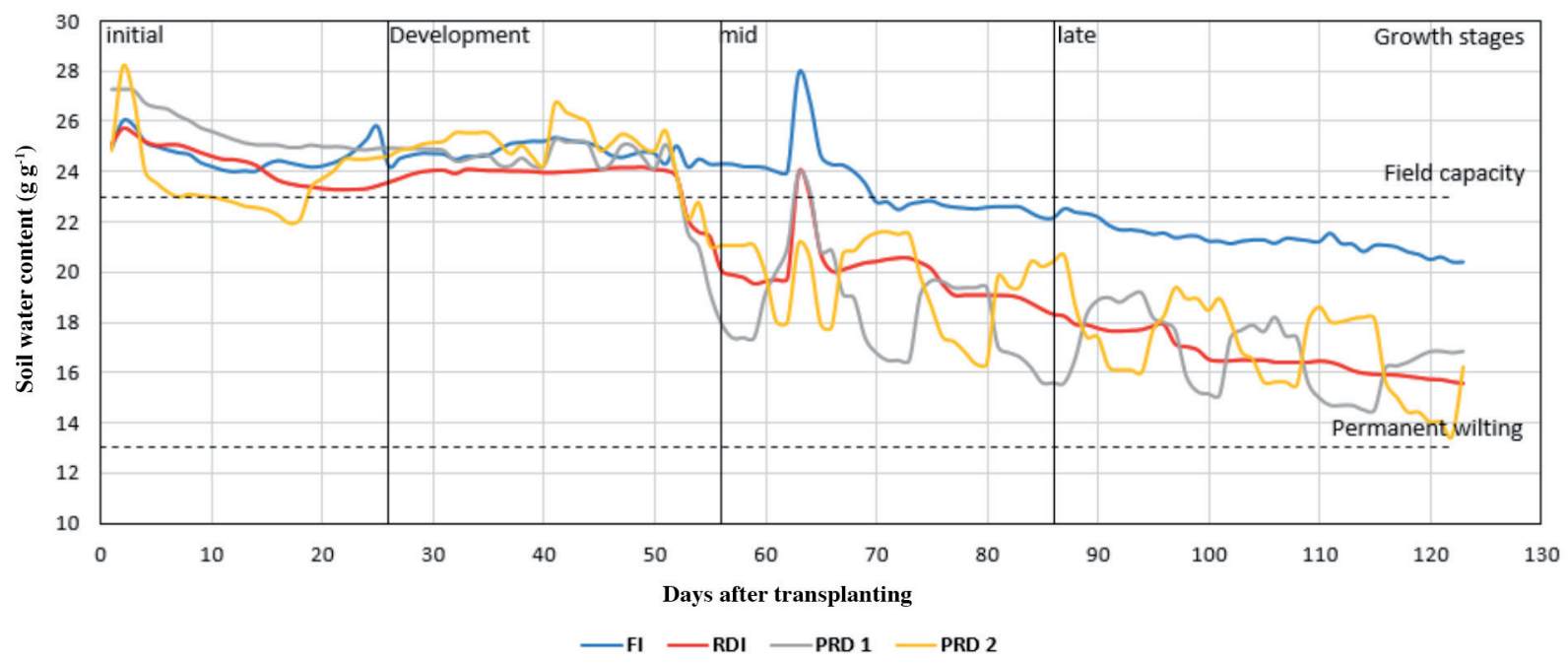


Figure 3. Soil water content (SWC) distribution in tomatoes field under different irrigation treatments: full irrigation (FI), regulated deficit irrigation (RDI), and partial root zone drying irrigation (PRD) in the $2^{\text {nd }}$ year, from the $1^{\text {st }}$ day until the $125 \mathrm{~d}$ after transplanting.

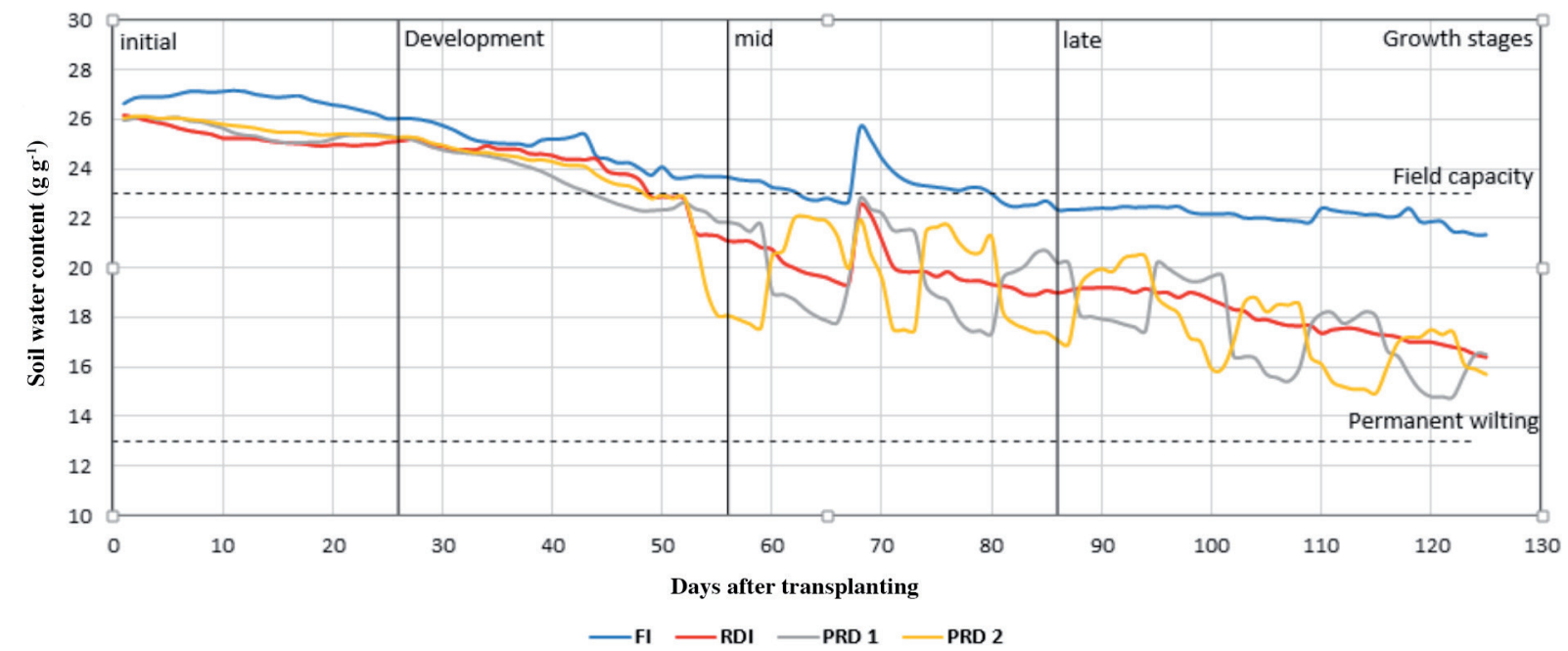

level between FC and WP without plant water stresses. The SWC data under different treatments (Figures 2 and 3) exhibited different patterns of water distribution in response to tomato watering treatment. This was due to the different amounts of water applied in each treatment and growth stage. The SWC was influenced by root development and water extraction. As shown in Figures 2 and 3, the SWC for RDI and PRD treatments were lower than those of the FI treatments for both years.

The daily SWC of FI was close to the water field capacity for both years. Correspondingly, the applied deficit irrigation treatments resulted in a decrease in SWC and remained at approximately $15-20 \mathrm{~g} \mathrm{~g}^{-1}$ for the $1^{\text {st }}$ year and ranged between 16-21 $\mathrm{g} \mathrm{g}^{-1}$ for the $2^{\text {nd }}$ year (Figures 2 and 3). Alternate wetting and drying cycles that result from applying PRD treatments affected SWC in the root-zones (Figures 2 and 3). Therefore, the SWC in PRD root-zone alternately increased and decreased for both PRD lines in the opposite direction.

Figures 2 and 3 indicated that the irrigation switch was applied every $7 \mathrm{~d}$ to keep the roots alive, and signaling was sustained. Thus, the differences in SWC between the PRD wet and dry sides were observed during the deficit irrigation treatment application. Despite a significant contrast in the soil water content between the two sides of the PRD (PRD1 and PRD2), the PRD treatment average SWC was close to that of the RDI treatment, thereby indicating that the rates of water use were fundamentally the same between the two treatments. The monitoring of SWC in the PRD treatment indicated a change in root-zone uptake in response to the irrigation method. However, there exist a few lateral soil water movements from the wet side to the dry side after each watering. The results demonstrate that the SWC in each PRD root-zone alternately increased and decreased. This result is in agreement with the results of extant studies on PRD (Kirda et al., 2004).

A similar pattern of soil water dynamics was also observed in PRD-treated tomato and other crops (Zegbe-Domínguez et al., 2006). A higher rate of water uptake in the final stage (Figures 2 and 3) is potentially due to the increased root contact area or improved root hydraulic conductivity after re-watering the dry side as shown by Kang et al. (2001). The un-watered side of the root zone in PRD exhibited a reduction in SWC although sufficient water was available in the wet side of the root zone to supply adequate water to the roots of the plant to maintain plant growth although at a lower level when compared to the FI treatment. With respect to the comparison between PRD and RDI (in which the same amount of water was applied).

The effects of irrigation treatments on stomatal conductance $\left(g_{s}\right)$ are shown in Figure 4. In the $1^{\text {st }}$ year, $g_{s}$ values in different irrigation treatments in the study varied mainly between 0.16 and $0.8 \mathrm{~mol} \mathrm{~m}^{-2} \mathrm{~s}^{-1}$. In the $2^{\text {nd }}$ year, $\mathrm{g}_{\mathrm{s}}$ values varied mainly between 0.12 and $0.87 \mathrm{~mol} \mathrm{~m}^{-2} \mathrm{~s}^{-1}$ (Figure 4). For both years, the two water deficit irrigation treatments (RDI and PRD) exhibited $g_{s}$ values lower than those in the FI treatment. This indicates their stomatal closure because $g_{s}$ indicates the degree of stomata opening. This could occur due to the lower water content in both RDI and PRD when compared with 
Figure 4. Stomatal conductance for the irrigation.
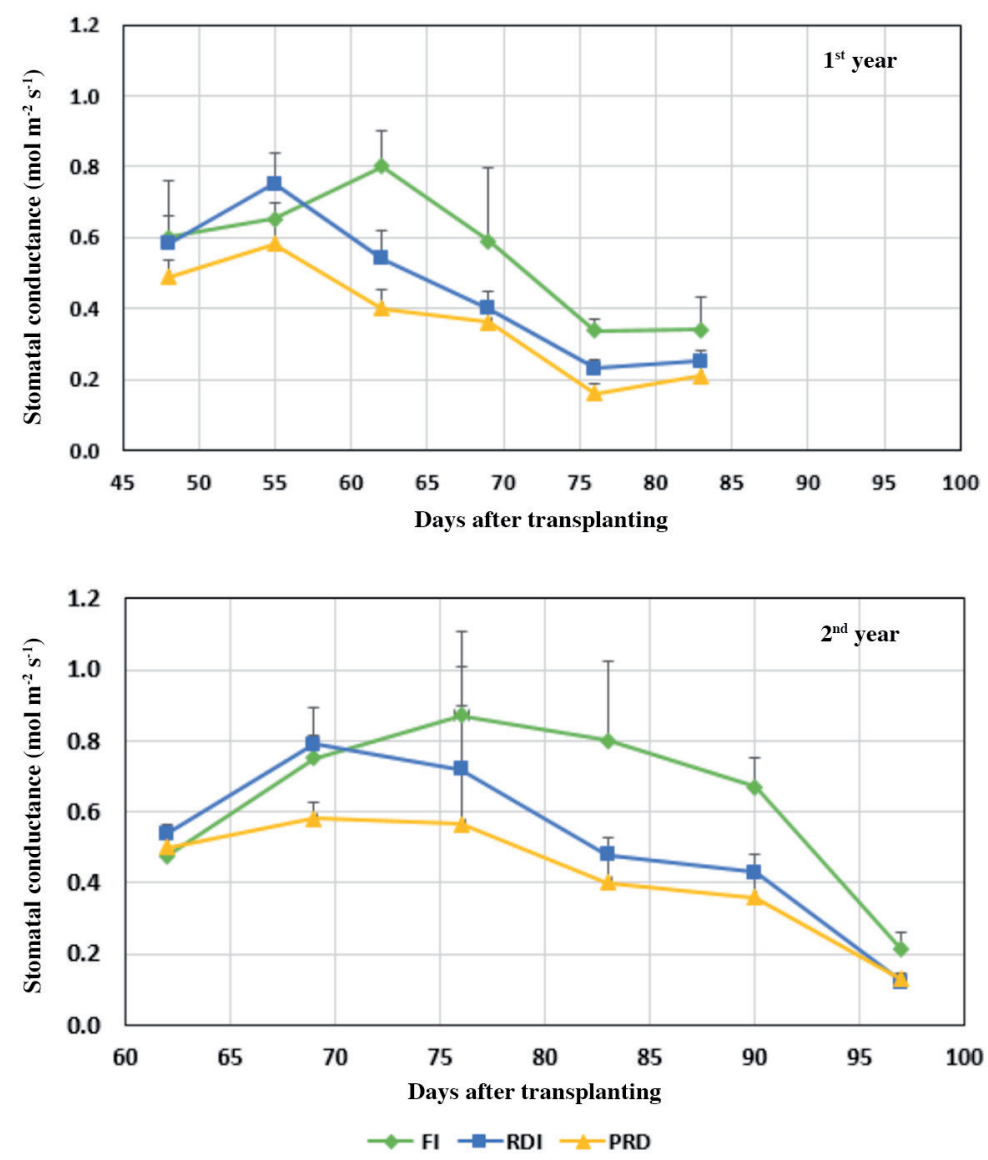

The data points represent means \pm standard error of the mean $(n=3)$.

FI: Full irrigation; RDI: regulated deficit irrigation; and PRD: partial root zone drying irrigation.

that in the FI treatment as mentioned previously. Consequently, the $\mathrm{g}_{\mathrm{s}}$ decreased although water stress on the plant was absent. Therefore, $g_{s}$ is considered as a common and important plant response to soil drying. These results were consistent with those obtained by Nardella et al. (2012), who reported that the process of stomatal closure was one of the initial events in plant response to soil drying and water stress. Stomatal closure aided in preventing excessive water loss in plants due to transpiration and leads to a better water balance.

In the $1^{\text {st }}$ year, RDI and PRD decreased $\mathrm{g}_{\mathrm{s}}$ when compared with FI treatment by $16.99 \%$ and $33.82 \%$, respectively. Nevertheless, in the $2^{\text {nd }}$ year, the results exhibited that RDI and PRD decreased the average value of $g_{s}$ by $18.70 \%$ and $32.96 \%$, respectively, when compared with those in the FI. This indicated that FI exhibited the highest $g_{s}$ values and the PRD exhibited the lowest $g_{s}$ values among all the treatments. This is potentially because the PRD led to stomatal closure since frequent switches in irrigation from one side of the PRD plants to another could maintain a larger portion of the roots that is exposed to water stress when compared to RDI where more of the root system was in the dry soil. This was clear from the soil water content as shown previously in Figures 3 and 4. An increase in the portion of roots exposed to drying soil with PRD may result in the arrival of increased ABA in the leaves that affects stomatal opening, and thereby reduces water loss. In the $1^{\text {st }}$ year, it was nonsignificantly different between RDI and PRD although there was a significant difference $(\mathrm{p}>0.05)$ between deficit irrigation treatments and FI with respect to 62,76 , and $82 \mathrm{~d}$ after transplanting (DAT). In the $2^{\text {nd }}$ year, the effects of irrigation treatments on $g_{s}$ were nonsignificant although the fifth reading indicated significant effects for irrigation treatments on $\mathrm{g}_{\mathrm{s}}$. 
Figure 5 shows the effects of the irrigation treatments on the transpiration rate $(\mathrm{T})$ of tomato plants for both years of the study. Figure 5 shows that RDI and PRD treatments decreased the transpiration rate. The $\mathrm{T}$ values in the $1^{\text {st }}$ year ranged between 1.30 and $4.0 \mathrm{mmol} \mathrm{m}^{-2} \mathrm{~s}^{-1}$. However, $\mathrm{T}$ values in the $2^{\text {nd }}$ year varied from 1.61 to $4.31 \mathrm{mmol} \mathrm{m}^{-2} \mathrm{~s}^{-1}$ (Figure 5). Generally, in both years, the trend of transpiration rate increased up to mid-season and then decreased. As shown in Figure 5, the lowest value of the transpiration rate in the $1^{\text {st }}$ year $\left(1.30 \mathrm{mmol} \mathrm{m}^{-2} \mathrm{~s}^{-1}\right)$ was observed with PRD. However, the highest value $\left(4.00 \mathrm{mmol} \mathrm{m}^{-2} \mathrm{~s}^{-1}\right)$ was obtained with FI. However, in the second year, the lowest value $\left(1.61 \mathrm{mmol} \mathrm{m}^{-2}\right.$ $\left.\mathrm{s}^{-1}\right)$ was obtained with RDI, and the highest value $\left(4.21 \mathrm{mmol} \mathrm{m}^{-2} \mathrm{~s}^{-1}\right)$ was obtained with FI. It was observed that the water saving irrigation techniques (RDI and PRD) decreased the average value of T, when compared with FI treatment, by $15 \%$ and $23 \%$, respectively, in the $1^{\text {st }}$ year. Nevertheless, in the $2^{\text {nd }}$ year, the results indicated that the measurements under RDI and PRD decreased the average value of $\mathrm{T}$ by $14.17 \%$ and $8.8 \%$, respectively, when compared with those in the FI. This occurred because the water content decreased under DI treatments, and thus the abscisic acid concentration increased and triggered the closure of stomata (Gollan et al., 1992), and thereby reduced the transpiration water loss and improved WUE. The results were consistent with those obtained by previous studies including Nangare et al. (2016) that indicated lower $T$ values under drought stress conditions in tomato crop. Yang et al. (2012) concluded that the PRD reduced the leaf transpiration rate of tomato crop when compared to that in FI treatment.

ANOVA indicated the absence of significant differences between RDI and PRD with respect to the effect on transpiration rate for both years. These results indicate that the RDI and PRD are good methods to reduce the transpiration rate, and thereby conserve water.

Figure 5. Transpiration rate of the tomato crop for different irrigation treatments.
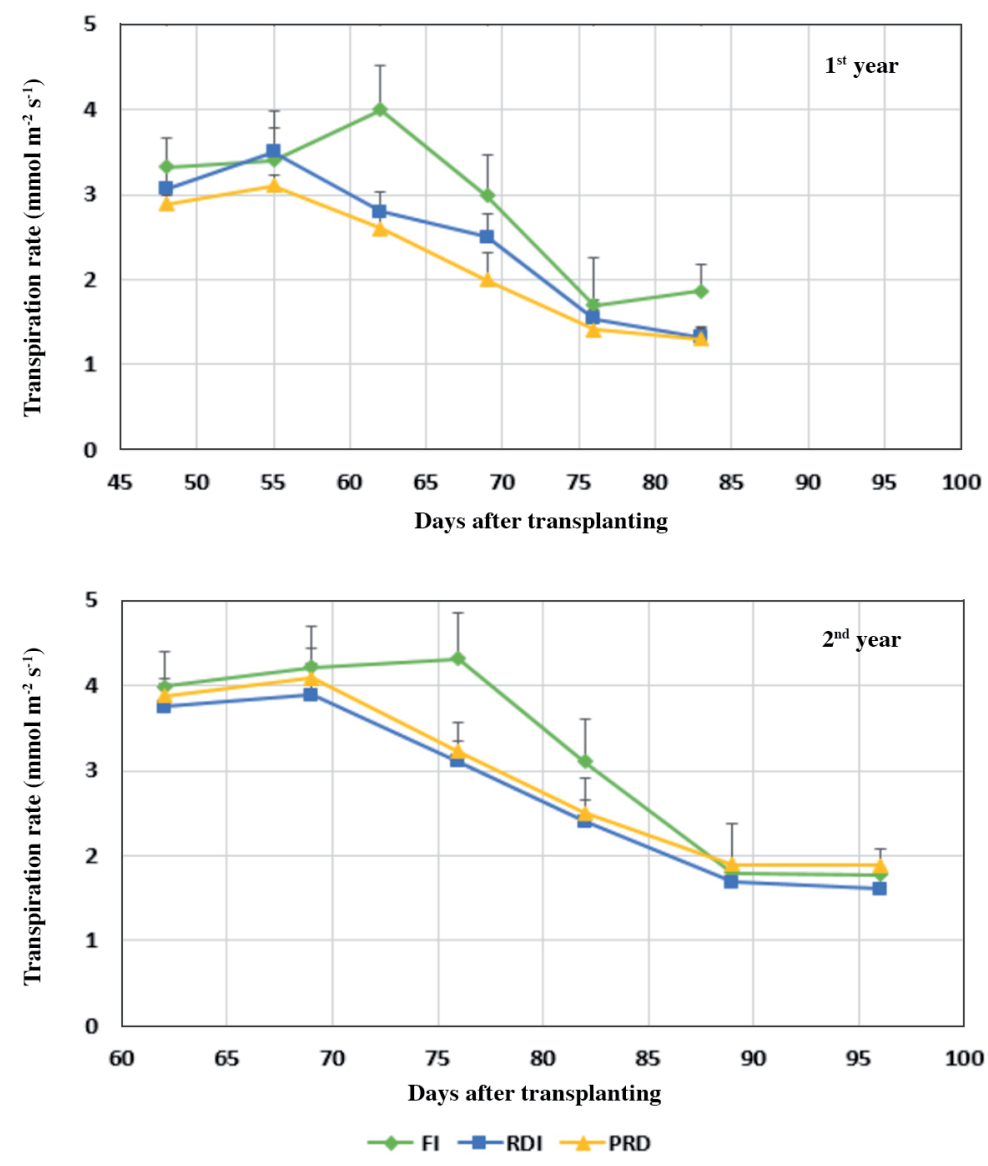

The data points represent means \pm standard error of the mean $(n=3)$.

FI: Full irrigation; RDI: regulated deficit irrigation; and PRD: partial root zone drying irrigation. 
The effects of the irrigation treatments on xylem abscisic acid in the tomato crop are shown in Figure 6. The results indicated that the water-saving treatments increased the ABA content of the tomato crop when compared to the FI treatment.

The ABA content of tomato crop was the highest under PRD treatment when compared to FI and RDI treatments in the $1^{\text {st }}$ year as shown in Table 4 and Figure 6. The RDI treatment in which the same amount of irrigation water was received as the PRD treatment exhibited an intermediate ABA concentration between the FI and PRD treatments although it was closer to PRD than FI. In the $2^{\text {nd }}$ year, ABA concentration was the highest under RDI. The FI exhibited the lowest xylem ABA concentration (Figure 6). During the $1^{\text {st }}$ year, xylem ABA concentration for PRD and RDI exceeded FI by $21.61 \%$ and $18.64 \%$, respectively. In the $2^{\text {nd }}$ year, xylem ABA concentration for PRD and RDI exceeded FI by $8.59 \%$ and $25.25 \%$, respectively. The increase in ABA concentration occurred because the soil water status in the root zone under PRD and RDI treatments was low when compared with FI treatments, and this significantly influenced the ABA concentration in the xylem. The results were consistent with those obtained by Wang et al. (2012), who revealed a significant negative linear relationship between root water potential and the xylem ABA concentration.

Liu et al. (2003) concluded that hydraulic signals are significant when the soil water deficit is severe. This helps the synthesis of ABA in the leaves and maybe adds to controlling the plant's responses to dryness by a decrease in the leaf turgor and $\mathrm{g}_{\mathrm{s}}$ (Liu et al., 2003). ANOVA showed that there is a notable effect $(\mathrm{p}<0.05)$ of different irrigation treatments on ABA content for both years. The results were consistent with Sun et al. (2013), who suggested that the reduced irrigation regimes significantly affected ABA. Akhtar et al. (2014) indicated that leaf ABA contents were higher under RDI and PRD when compared with FI.

Figure 6. Xylem abscisic acid ( $\mathrm{ABA}$ ) concentration for the tomato crop on 1 December (67 d after transplanting) for the different irrigation treatments in both years.

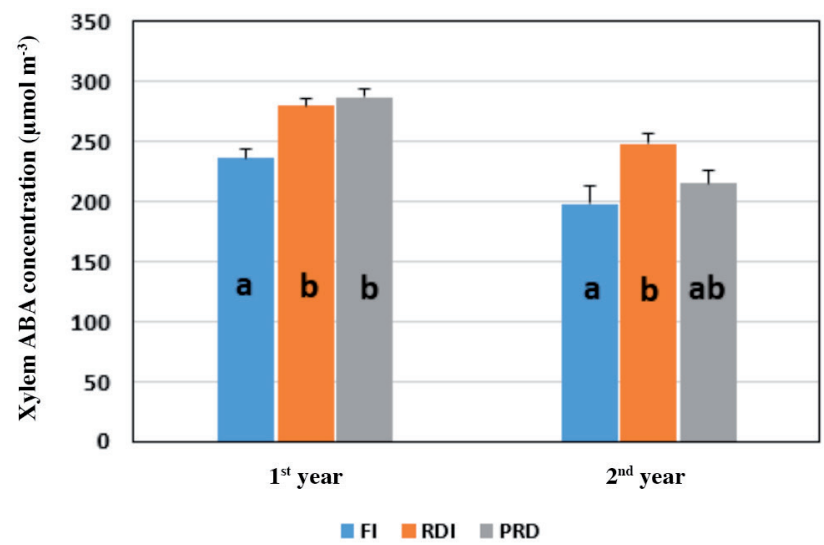

Different letters inside columns exhibited significant differences between irrigation treatments at $\mathrm{p}<$ 0.05 . Bars denote the means \pm standard error of the mean $(n=3)$.

FI: Full irrigation; RDI: regulated deficit irrigation; and PRD: partial root zone drying irrigation.

Table 4. Xylem abscisic acid (ABA) concentration for the tomato crop on 1 December ( $67 \mathrm{~d}$ after transplanting) for the different irrigation treatments in both years.

\begin{tabular}{|c|c|c|}
\hline \multirow[b]{2}{*}{ Treatments } & \multicolumn{2}{|c|}{ Xylem [ABA] } \\
\hline & $1^{\text {st }}$ year & $2^{\text {nd }}$ year \\
\hline $\mathrm{FI}$ & 236 & 198 \\
\hline RDI & 280 & 248 \\
\hline PRD & 287 & 215 \\
\hline
\end{tabular}

FI: Full irrigation; RDI: regulated deficit irrigation; PRD: partial root zone drying irrigation. 
Fresh, dry fruit yield per hectare (FW, DW), and the number of fruits per plant for the different irrigation treatments in tomato are shown in Table 5 and Figure 7. Generally, the highest tomato fruit yield was obtained under the full irrigation treatment in the $1^{\text {st }}$ year and $2^{\text {nd }}$ year. This potentially occurred because the soil water content under FI exceeded that in DI treatments.

The lowest fruit yield in $1^{\text {st }}$ year was obtained under RDI $\left(48.72 \mathrm{Mg} \mathrm{ha}^{-1}\right)$ and the lowest fruit yield was obtained under RDI (53.37 Mg ha-1) in the $2^{\text {nd }}$ year (Figure 7). In the $1^{\text {st }}$ year, yield reduction under RDI and PRD treatments corresponded to $14.07 \%$ and $9.64 \%$, respectively, when compared with FI, while the yield reductions under RDI and PRD treatment in the $2^{\text {nd }}$ year were $12.75 \%$ and $9.19 \%$, respectively, when compared with FI.

Table 5. Fruit yield traits of tomato for the different irrigation treatments in both years.

\begin{tabular}{lcccc}
\hline & Treatments & Fruit FW & Fruit DW & $\mathrm{Nr}$ fruit plant $^{-1}$ \\
\hline \multirow{3}{*}{$1^{\text {st }}$ year } & & $\mathrm{Mg} \mathrm{ha}^{-1}$ & $\mathrm{Mg} \mathrm{ha}^{-1}$ & \\
& FI & 56.70 & 3.69 & 25 \\
& RDI & 48.72 & 3.98 & 22 \\
$2^{\text {nd }}$ year & PRD & 51.23 & 4.21 & 23 \\
& FI & 61.17 & 3.80 & 26 \\
& RDI & 53.37 & 4.16 & 23 \\
& PRD & 55.55 & 4.32 & 25 \\
\hline
\end{tabular}

FW: Fresh weight; DW: dry weight; FI: Full irrigation; RDI: regulated deficit irrigation; PRD: partial root zone drying irrigation.

Figure 7. Fresh (FW) and dry weight (DW) tomato fruit yield per hectare for different irrigation treatments.
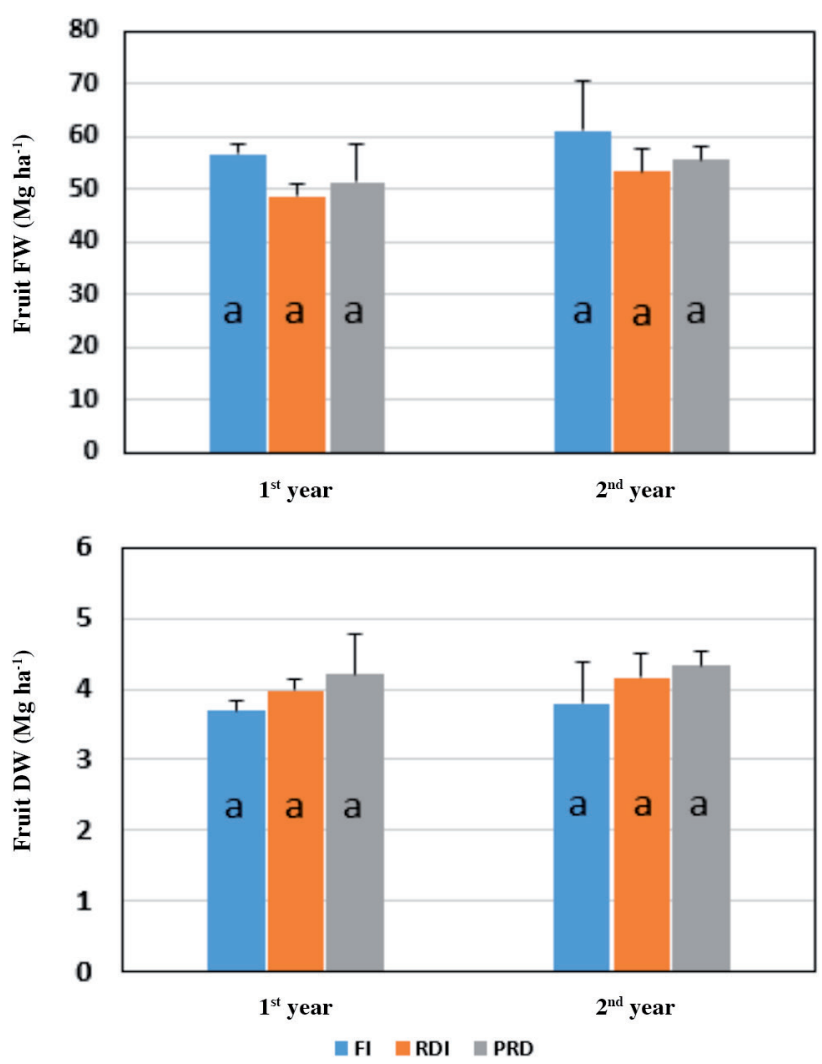

Different letters inside columns denote significant differences between irrigation treatments at $\mathrm{p}<0.05$.

Bars denote the means \pm standard error of the mean $(n=3)$.

FI: Full irrigation; RDI: regulated deficit irrigation; and PRD: partial root zone drying irrigation. 
The explanation for the reduction is that the drying of soil decreases the rate of absorption by roots below the transpiration rate by the plant, and thus constitutes an internal water deficit that affects photosynthesis and results in reduced leaf area, intercellular volume, and cell size. This in turn reduces soil moisture accumulation. The effect of the internal water deficit was higher at the fruit growth stage as the expanding fruit tissues require considerable water at this time.

It is assumed that higher fresh weight of FI fruits is the result of a longer ripening period that allowed higher accumulation of water in these fruits when compared to DI fruits (Savic et al., 2008). The results obtained by several previous studies support the present study results. For example, Kirda et al. (2004) and Giuliani et al. (2016) indicated that the marketable yield under FI treatment was the highest values comparing with RDI and PRD. Kuscu et al. (2014) reported that the highest marketable tomato yields were observed with full irrigation, and a decrease in the irrigation rate generally improved the DM of fresh tomato fruits. According to the dry fruit yield responses, the results generally indicated that the deficit irrigation treatments increased the dry fruit yield for most measurements. Evidently, the effect of irrigation method on dry fruit yield was absent. The results in $1^{\text {st }}$ year indicated that the dry fruit yield was the lowest for FI (3.69 Mg ha-1) and the highest (4.21 Mg ha-1) for PRD treatment as shown in Figure 7. The results in the $2^{\text {nd }}$ year revealed that the lowest value of dry fruit yield was observed with FI (3.80 $\left.\mathrm{Mg} \mathrm{ha}^{-1}\right)$. Conversely, the highest value was observed with PRD (4.32 $\left.\mathrm{Mg} \mathrm{ha}^{-1}\right)$.

Water stress applied to the tomatoes led to an increase in concentrations of sugar and DM of ripe fruit. These phenomena are explained by the fact that water stress did not affect the quantity of DM accumulated by the fruit although it significantly reduced its accumulation of water (Mitchell et al., 1991).

Figure 8 shows a decreasing trend in the number of fruit per plant values under deficit irrigation. A plausible explanation for this was that the average number of flowers per truss decreased with decreases in the water supply. This is consistent with the results of Prieto Losada and Rodriguez del Rincón (1993), who indicated that water stress during flowering reduced the number of flowers. In the $1^{\text {st }}$ year, the number of fruits per plant for RDI and PRD decreased when compared with that of FI by $12 \%$ and $8 \%$, respectively. However, in the $2^{\text {nd }}$ year, RDI and PRD decreased the number of fruit per plant by $11.54 \%$ and $3.85 \%$, respectively, when compared with FI. The reduction in the fruits number in RDI and PRD (Figure 8) is possibly the result of floral abortion induced by water deficit (Pulupol et al., 1996). Figure 8 shows a decrease in or absence of a significant effect that supports the absence of a pronounced decrease. Furthermore, our results are consistent with those obtained by Zegbe-Domínguez et al. (2003), who suggested that the number of fruits in the tomato crop and fruit water content reduced in RDI and PRD relative to FI. ANOVA in both years indicated that was nonsignificant effect $(\mathrm{p}>0.05)$ to irrigation treatments on fresh, dry fruit yield, and fruit number per plant.

The goal of DI is to enhance irrigation water use efficiency (IWUE) by decreasing the amount of water applied with irrigation or by reducing the number of irrigation events (Kirda et al., 2004). Thus, the irrigation water applied (IWA)

Figure 8. Number of tomato fruits per plant for the different irrigation treatments.

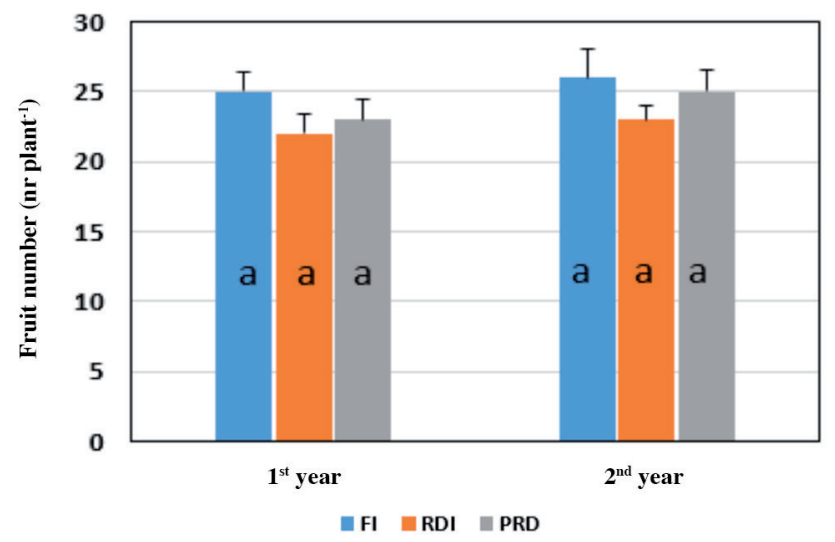

Different letters inside columns revealed significant differences between irrigation treatments at $\mathrm{p}<0.05$.

Bars denote the means \pm standard error of the mean $(n=3)$.

FI: Full irrigation; RDI: regulated deficit irrigation; and PRD: partial root zone drying irrigation. 
amount for the tomato crop under all treatments (FI, RDI, and PRD) during the $2 \mathrm{yr}$ was recorded (Table 6). The higher amount of applied water at the second season occurred due to the relative humidity was very low at the $2 \mathrm{yr}$ comparing with $1 \mathrm{yr}$. IWUE values determined for all irrigation treatments are also shown in Figure 9.

With respect to all treatments for the $2 \mathrm{yr}$, there are nonsignificant effects $(\mathrm{p}>0.05)$ on IWUE values. Similarly, the effects of water stress on the IWUE as indicated by several researchers corresponded to the absence of noteworthy differences in IWUE relative to the different water regimes that were used (Giuliani et al., 2016).

In the first year, although there were nonsignificant differences between treatments, IWUE values were 18.34 and $18.89 \mathrm{~kg} \mathrm{~m}^{-3}$ for RDI and PRD, respectively, which were higher than those for FI $\left(17.05 \mathrm{~kg} \mathrm{~m}^{-3}\right)$ by $7.57 \%$ and $10.8 \%$, respectively. During the second year, the IWUE values for RDI, PRD, and FI were 14.83, 15.31, and $13.77 \mathrm{~kg} \mathrm{~m}^{-3}$, respectively. Accordingly, the IWUE for both RDI and PRD exceeded FI by $7.7 \%$ and $11.18 \%$, respectively. Thus, the vast majority of most extreme IWUE values was observed under PRD. However, most of the smallest IWUE values were coupled with FI. These results denote the impacts of deficit levels on IWUE. In most extant studies, increases in the IWUE in tomato were reported under water deficit conditions (Kirda et al., 2004). It was previously observed that the results were consistent with those obtained by Nardella et al. (2012), who illustrated that the IWUE values obtained from PRD and RDI strategies exceeded that of FI, and they reported that PRD strategy exhibited slightly higher IWUE values when compared to RDI.

Kirda et al. (2004) performed a greenhouse experiment by using the restoration of $70 \% \mathrm{ET}_{\mathrm{c}}$ and indicated that IWUE improvements on fresh-market tomato corresponded to $11.5 \%$ and $5.5 \%$ under PRD and DI, respectively. Nangare et al. (2016) reported maximum water productivity under RDI80 when deficit irrigation was applied.

Yang et al. (2012) reported that alternate PRD improved IWUE when compared to conventional irrigation. Akhtar et al. (2014) suggested that IWUE in PRD exceeded that in RDI. The increase in IWUE values under the two DI practices is attributed to the partial stomatal closure observed under RDI and PRD treatments that leads to a decrease in $\mathrm{T}$ and potentially to an increase in WUE.

Table 6. Irrigation water applied (IWA) per hectare.

\begin{tabular}{llll}
\hline & \multicolumn{2}{c}{ IWA } \\
\cline { 2 - 2 } Treatments & \multicolumn{2}{c}{ 1 $^{\text {st } y e a r ~}$} & $2^{\text {nd }}$ year \\
\cline { 2 - 2 } ha $^{-1}$ & & \\
FI & 3325.10 & & 4443.39 \\
RDI & 2656.99 & & 3599.22 \\
PRD & 2712.65 & & 3627.80 \\
\hline
\end{tabular}

FI: Full irrigation; RDI: regulated deficit irrigation; PRD: partial root zone drying irrigation.

Figure 9. Irrigation water use efficiency (IWUE) for the different irrigation treatments in tomato.

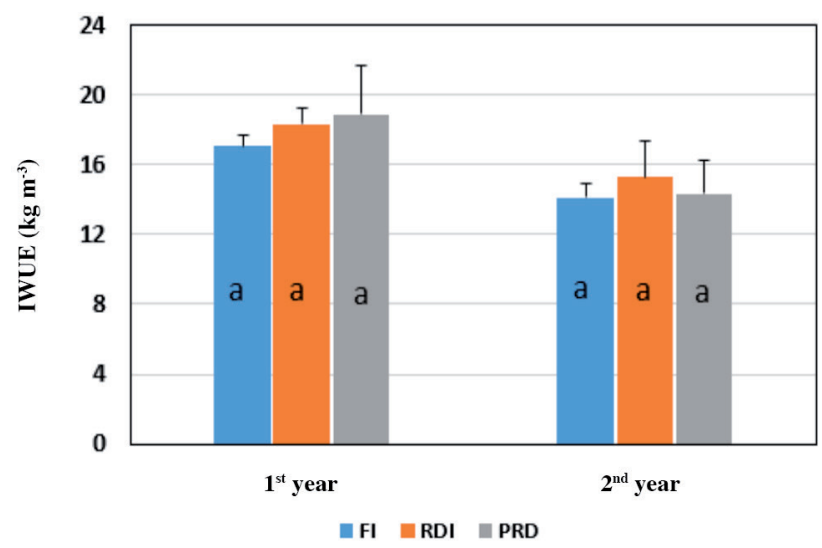

Different letters inside columns denote significant differences between irrigation treatments at $\mathrm{p}<0.05$.

Bars denote the means \pm standard error of the mean $(n=3)$.

FI: Full irrigation; RDI: regulated deficit irrigation; and PRD: partial root zone drying irrigation. 


\section{CONCLUSIONS}

From all of the above field experimental results, partial root-zone drying and regulated deficit irrigation techniques have proven the efficiency in improving the irrigation water use efficiency and fruit quality and dry fruit yield as compared to full irrigation. In particular, partial root zone drying irrigation, which is the recommended treatment for saving water and maintaining yield.

\section{ACKNOWLEDGEMENT}

This Project was funded by the National Plan for Science, Technology and Innovation (MAARIFAH), King Abdulaziz City for Science and Technology, Kingdom of Saudi Arabia, Award Number (11-WAT1978-02).

\section{REFERENCES}

Afshar, R.K., Jovini, M.A., Chaichi, M.R., and Hashemi, M. 2014. Grain sorghum response to arbuscular mycorrhiza and phosphorus fertilizer under deficit irrigation. Agronomy Journal 106(4):1212-1218.

Ahmadi, S.H., Andersen, M.N., Plauborg, F., Poulsen, R.T., Jensen, C.R., Sepaskhah, A.R., et al. 2010. Effects of irrigation strategies and soils on field-grown potatoes: Gas exchange and xylem [ABA]. Agricultural Water Management 97:1486-1494.

Akhtar, S.S., Li, G., Andersen, M.N., and Liu, F. 2014. Biochar enhances yield and quality of tomato under reduced irrigation. Agricultural Water Management 138:37-44.

Allen, R.G., Pereira, L.S., Raes, D., and Smith, M. 1998. Crop evapotranspiration- guidelines for computing crop water requirements. Irrigation and Drainage Paper Nr 56. FAO, Rome, Italy.

Asch, F. 2000. Determination of abscisic acid by indirect enzyme linked immunosorbent assay (ELISA). Technical Report. Laboratory for Agrohydrology and Bioclimatology, Department of Agricultural Sciences, Royal Veterinary and Agricultural University, Taastrup, Denmark.

Comstock, J.P. 2002. Hydraulic and chemical signaling in the control of stomatal conductance and transpiration. Journal of Experimental Botany 53:195-200.

De Pascale, S., Dalla Costa, L., Vallone, S., Barbieri, G., and Maggio, A. 2011 . Increasing water use efficiency in vegetable crop production: from plant to irrigation systems efficiency. HortTechnology 21(3):301-308.

English, M., and Raja, S.N. 1996. Perspectives on deficit irrigation. Agricultural Water Management 32:1-14.

Giuliani, M.M., Gatta, G., Nardella, E., and Tarantino, E. 2016. Water saving strategies assessment on processing tomato cultivated in Mediterranean region. Italian Journal of Agronomy 11(1):69-76.

Gollan, T., Passioura, J.B., and Munns, R. 1992. Soil-water status affects the stomatal conductance of fully turgid wheat and sunflower leaves. Australian Journal of Plant Physiology 13:459-464.

Kang, S., Zhang, L., Hu, X., Li, Z., and Jerie, P. 2001. An improved water use efficiency for hot pepper grown under controlled alternate drip irrigation on partial roots. Scientia Horticulturae 89:257-267.

Kirda, C., Cetin, M., Dasgan, Y., Topcu, S., Kaman, H., Ekici, B., et al. 2004. Yield response of greenhouse grown tomato to partial root drying and conventional deficit irrigation. Agricultural Water Management 69(3):191-201.

Kriedemann, P.E., and Goodwin, I. 2003a. Regulated deficit irrigation and partial rootzone drying. Irrigation Insights Nr 4. 102 p. Land and Water Australia, Canberra, Australia.

Kuscu, H., Turhan, A., Ozmen, N., Aydinol, P., and Demir, A.O. 2014. Optimizing levels of water and nitrogen applied through drip irrigation for yield, quality, and water productivity of processing tomato (Lycopersicon esculentum Mill.) Horticulture, Environment, and Biotechnology 55(2):103-114.

Liu, F., Jensen, C.R., and Andersen, M.N. 2003. Hydraulic and chemical signals in the control of leaf expansion and stomatal conductance in soybean exposed to drought stress. Functional Plant Biology 30:65-73.

Liu, F., Shahnazari, A., Andersen, M.N., Jacobsen, S.E., and Jensen, C.R. 2006. Physiological responses of potato (Solanum tuberosum L.) to partial root-zone drying: ABA signaling, leaf gas exchange, and water use efficiency. Journal of Experimental Botany 57:3727-3735.

Mitchell, J.P., Shennan, C., and Grattan, S.R. 1991. Developmental changes in tomato fruit composition in response to water deficit and salinity. Physiologia Plantarum 83:177-185.

Nangare, D.D., Singh, Y., Kumar,P.S., and Minhas, P.S. 2016. Growth, fruit yield and quality of tomato (Lycopersicon esculentum Mill.) as affected by deficit irrigation regulated on phenological basis. Agricultural Water Management 171:73-79.

Nardella, E., Giuliani, M.M., Gatta, G., and De Caro, A. 2012. Yield response to deficit irrigation and partial root-zone drying in processing tomato (Lycopersicon esculentum Mill.) Journal of Agricultural Science and Technology A2:209-219. 
Prieto Losada, H., and Rodriguez del Rincón, A. 1993. Influence of the crop water status on fruit setting and final fruit number in a processing tomato crop. Acta Horticulturae 376:333-336.

Pulupol, L.U., Behboudian, M.H., and Fisher, K.J. 1996. Growth, yield and postharvest attributes of glasshouse tomatoes produced under deficit irrigation. American Society for Horticultural Science 31:926-929.

Romero, P., Pérez-Pérez, J.G., Del Amor, F., Martínez-Cutillas, A., Dodd, I.C., and Botía, P. 2014. Partial root zone drying exerts different physiological responses on field-grown grapevine (Vitis vinifera cv. Monastrell) in comparison to regulated deficit irrigation. Functional Plant Biology 41(11):1087-1110.

Ruiz-Sanchez, M.C., Domingo. R., and Castel S.J.R. 2010. Review. Deficit irrigation in fruit trees and vines in Spain. Journal of Agricultural Research 8(S2):S5-S20.

Salghi, R.N., Affi, A., El Fadl, M., El Otmani, M., Benismail, C., Idrissi, L.M., et al. 2012. Comparative effects of partial rootzone drying and deficit irrigation on physiological parameters of tomato crop. Der Pharma Chemica 4(6):2402-2407.

Savic, S., Stikic, R., Radovic, B.V., Bogicevic, B., Jovanovic, Z., and Sukalovic, V.H.T. 2008. Comparative effects of regulated deficit irrigation (RDI) and partial root-zone drying (PRD) on growth and cell wall peroxidase activity in tomato fruits. Scientia Horticulturae 117(1):15-20.

Sepaskhah, A.R., and Ahmadi, S.H. 2010. A review on partial root-zone drying irrigation. International Journal of Plant Production 4(4):241-258.

Shahabian, M., Samar, S.M., Talaie, A., and Emdad, M.R. 2012. Response of orange trees to deficit irrigation strategies in the north of Iran. Archives of Agronomy and Soil Science 58(3):267-276.

Shahnazari, A., Liu, F., Andersen, M.N., Jacobsen, S.E., and Jensen, C.R. 2007. Effects of partial root-zone drying on yield, tuber size and water use efficiency in potato under field conditions. Field Crops Research 100:117-124.

Sun, Y., Feng, H., and Liu, F. 2013. Comparative effect of partial root-zone drying and deficit irrigation on incidence of blossomend rot in tomato under varied calcium rates. Journal of Experimental Botany 64:2107-2116.

Wakrim, R., Wahbi, S., Tahi, H., Aganchich, B., and Serraj, R. 2005. Comparative effects of partial root drying (PRD) and regulated deficit irrigation (RDI) on water relations and water use efficiency in common bean (Phaseolus vulgaris L.) Agriculture, Ecosystems and Environment 106:275-287.

Wang, Y., Liu, F., and Jensen, C.R. 2012. Comparative effects of deficit irrigation and alternate partial root-zone irrigation on xylem pH, ABA and ionic concentrations in tomatoes. Journal of Experimental Botany 63(5):1907-1917.

White, S.C. 2007. Partial root zone drying and deficit irrigation in cotton for use under large mobile irrigation machines. PhD dissertation. University of Southern Queensland, Toowoomba, Queensland, Australia.

Yang, L., Qu, H., Zhang, Y., and Li, F. 2012. Effects of partial root-zone irrigation on physiology, fruit yield and quality and water use efficiency of tomato under different calcium levels. Agricultural Water Management 104:89-94.

Zegbe-Domínguez, J.A., Behboudian, M.H., and Clothier, B.E. 2006. Responses of 'Petopride' processing tomato to partial root-zone drying at different phonological stages. Irrigation Science 24:203-210.

Zegbe-Domínguez, J.A., Behboudian, M.H., Lang, A., and Clothier, B.E. 2003. Deficit irrigation and partial rootzone drying maintain fruit dry mass and enhance fruit quality in 'Petopride' processing tomato (Lycopersicon esculentum, Mill.) Scientia Horticulturae 98(4):505-510. 